\title{
On the Relation of Grain Orientation and Opening Crack of an Al-Cu-Mg Sheet
}

\author{
Cai Hu \\ Light Alloy Research Institute, Central South University, Changsha, China \\ Email:hucai2@hotmail.com
}

How to cite this paper: $\mathrm{Hu}, \mathrm{C}$. (2017) On the Relation of Grain Orientation and Opening Crack of an Al-Cu-Mg Sheet. Engineering, 9, 510-516.

https://doi.org/10.4236/eng.2017.95031

Received: May 4, 2017

Accepted: May 28, 2017

Published: May 31, 2017

Copyright $\odot 2017$ by author and Scientific Research Publishing Inc. This work is licensed under the Creative Commons Attribution International License (CC BY 4.0).

http://creativecommons.org/licenses/by/4.0/

\begin{abstract}
In this paper, the orientation of grains which adjacent to a developed opening crack was investigated by EBSD. A definition of $\theta$ has been came up with which represents the angle between the principal stress plane and each $\{111\}$ plane of the grains. Smaller $\theta$ means easier to crack. It gave a good explanation of the crack propagation throughout the grains. It also revealed that propagation path is along with the $\{111\}$ plane. This finding will give a prediction of tear properties and help us understanding the cracking mechanism and the behavior of tearing.
\end{abstract}

Keywords

Al-Cu-Mg Sheet, Tearing Crack, Grain Orientation, $\{111\}$ Plane, Crack Propagation

\section{Introduction}

High strength and high toughness aluminum alloys such as 2024 is the key materials of aviation industry. It should have good durability while under severe environment. Not only the strength but also fracture toughness plays an important role in application. Not until A.A. Griffith did people realize that the fracture can happen even under a load significantly less than the yield range if the surface is scratched [1]. After that the discipline of fracture mechanism developed quickly [2]. Grain orientation cannot be ignored if we discuss the fracture mechanism. The slip plane is the principal stress plane that can accelerate the cracking process [3]. Large misorientation angle can prevent the dislocation to penetrate so that it leads to more energy consuming and the crack growth rate is negative correlation of misorientation angle [4]. Crack propagation has a huge influent to the evaluation of the fracture toughness. The resistance to the crack propagation is a vital property of materials. Fatigue crack propagation behavior 
has been studied by lots of researchers [5] [6] [7]. The path of the fatigue crack has something to do with the slip plane of aluminum alloy. Tilt and twist angle is proposed to explain the crystallographic mechanism of crack propagates through the grain boundary [8]. It also can be found in H.C.P. metals that the deformation mechanism of dislocation slips [9]. Texture plays an important role in every kinds of crack. Even the intergranular stress corrosion crack has something to do with the crystallographic texture of the material [10]. Not only experiment but also simulation certified the theory that crack follows $\{111\}$ planes in F.C.C. metals [11]. Since its stress state differs from that of fatigue crack propagation, the propagation behavior of tearing differs from that of fatigue. In this paper, tear crack propagation inside the grain is focused to investigate the influence of grain orientation on the crack propagation and corresponding mechanism. For this purpose, EBSD is a useful method that can be observed both in one picture [9] [12] [13] [14] [15] [16]. If a specimen with a tear crack tip observed in EBSD, the relation between grain orientation and the crack propagation path will be found. In this work, we torn an aluminum sheet and observed grain orientations adjacent to an opening crack by EBSD. The close relationship of crack propagation path and the $\{111\}$ planes was revealed.

\section{Materials and Experiments}

A notched 2024-T39 aluminum sheet with a thickness of $0.3 \mathrm{~mm}$ was torn, which polished by 180\#, 320\#, 600\#, 800\#, 1000\#, 1200\#, 1500\# rough sand paper and $800 \#$, 1000\# fine sand paper before tearing. Loading stopped before the crack went edge opposite to the notch. The specimens for tearing are thin enough for tearing it easily, as well as minimize the influence of inner grains that can't observe. It treated by annealing of $200^{\circ} \mathrm{C}, 1 \mathrm{~h}$ to release the residual stress. Twin-jet electro polishing was conducted before EBSD. EBSD data was acquired in FEI Helios Nanolab 600i with a step length of $6 \mu \mathrm{m}$.

\section{Results and Discussion}

In order to measure how the orientation influence the crack propagation, the Euler angles and the $\{111\}$ pole figures of the related grains $A, B, C, D$, and $\mathrm{E}$ were showed in Figure 1. The EBSD patterns were analyzed by OIM software. IPF map was automatic generation. And the $\{111\}$ pole figures were calculated from Euler angles of each grains and generated also from OIM. The crack came from the grain boundary of grain A and C, then came across the grain D. Obviously the way of the crack changed the direction and reached grain $\mathrm{B}$. It has a $\langle 111\rangle$ direction that close to the transverse direction, which makes it vulnerable to the crack along the rolling direction. The crack doesn't get through grain D. As crack reached the grain E, it stopped eventually. As showed in Figure 1 E, whose $\langle 111\rangle$ direction is far from the TD, the crack was arrested.

The crack resistance can be identified quantitatively by calculating the angle between all symmetrically equivalent $\{111\}$ plane and the principal stress plane. It's all known that $\{111\}$ has 8 corresponding plane of (111), (111), 

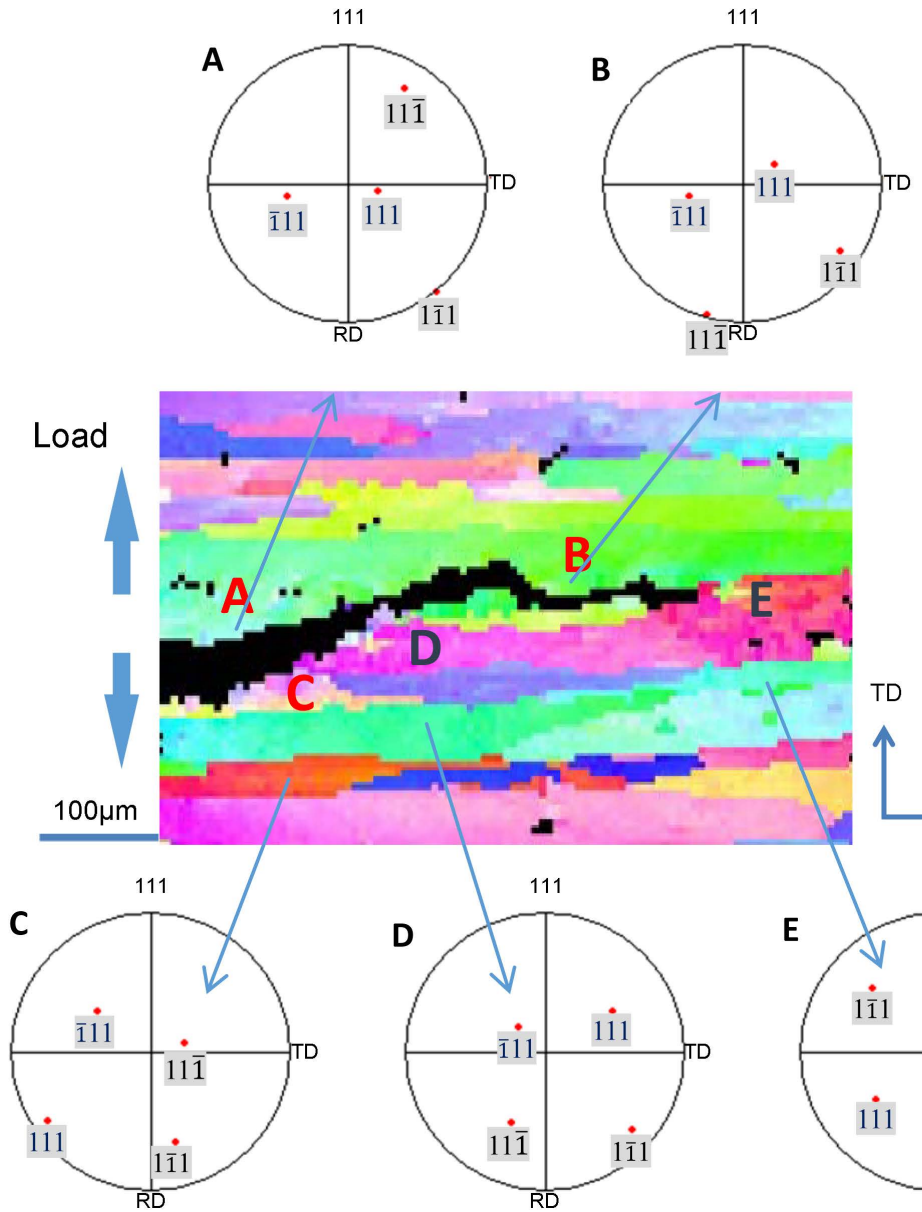

TD

TD
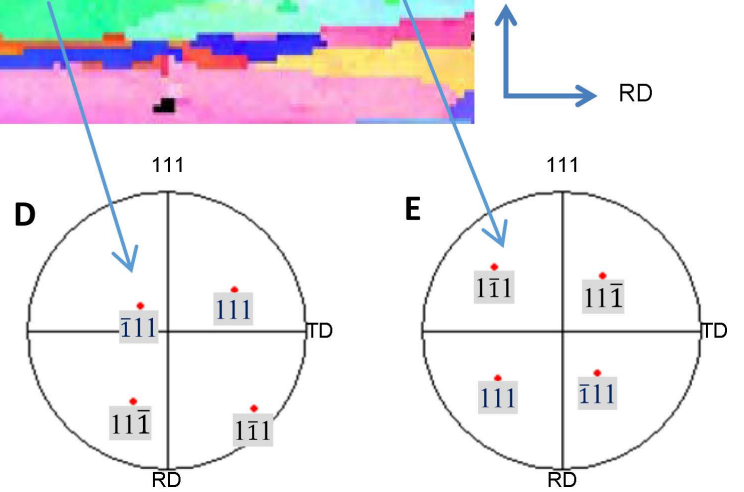

Figure 1. EBSD map of crack propagation.

$(1 \overline{1} 1),(11 \overline{1}),(\overline{1} \overline{1} 1),(\overline{1} 1 \overline{1}),(1 \overline{1} \overline{1})$ and $(\overline{1} \overline{1} \overline{1})$. All of them are taken into consideration. The principal stress plane denoted as (010) of the sample reference which is perpendicular to TD. Orientation matrixes were used in order to change the sample coordinate system to the crystal coordinate system. Here given a definition: $\theta$, represent the angle between principal stress plane (010) and each $\{111\}$ plane. Then every $\theta$ can be calculated. Figure 2 shows the definition of $\theta$. A principal stress plane (blue line) cut through a cubic crystal (black line). Red line shows each $\{111\}$ plane of this crystal. The cross line of (111) plane and principal stress plane are in purple. The angle between the (111) plane and principal stress plane called $\theta$.

The $\theta$ of each $\{111\}$ plane in every related grain are shown in the Table 1 . The $\theta$ larger than 90 degrees is equivalent as its counterpart of the number whose sum is 180 degrees. The $8\{111\}$ planes can be simplified into 4: (111), $(\overline{1} 11),(1 \overline{1} 1)$ and $(11 \overline{1})$.

It can be seen that the grain $\mathrm{B}$ has minor $\theta$ of 37.10 degrees compared to the 40.56 of the neighbor grain D. High angle of $\theta$ prevented the grains from being cut though by crack. It also can inhibit the crack propagation. The calculating of $\theta$ successfully revealed that the $\{111\}$ plane is easy to crack (Figure 1).

By testing the grains orientation, resistance level of crack propagation can be 
estimated. Furthermore, when using the appropriate processing method to change the grains orientation, tear properties as well as fracture toughness can be improved.

If only the crack is along $\{111\}$ plane, the path of the crack observed by us will be the intersection line of $\{111\}$ plane and the sheet plane in grain B. Figure 3 also shows the intersection lines (red lines) of $4\{111\}$ plane and the sheet plane in grain B. the crack path match the intersection line of (111), $(1 \overline{1} 1),(\overline{1} 11)$ plane obviously. This map clearly demonstrates the crack propagation along the (111) first then $(1 \overline{1} 1)$ finally $(\overline{1} 11)$ plane in grain $B$. $(11 \overline{1})$ is not cracked due to its large $\theta(72.94$ in Table 1$)$.

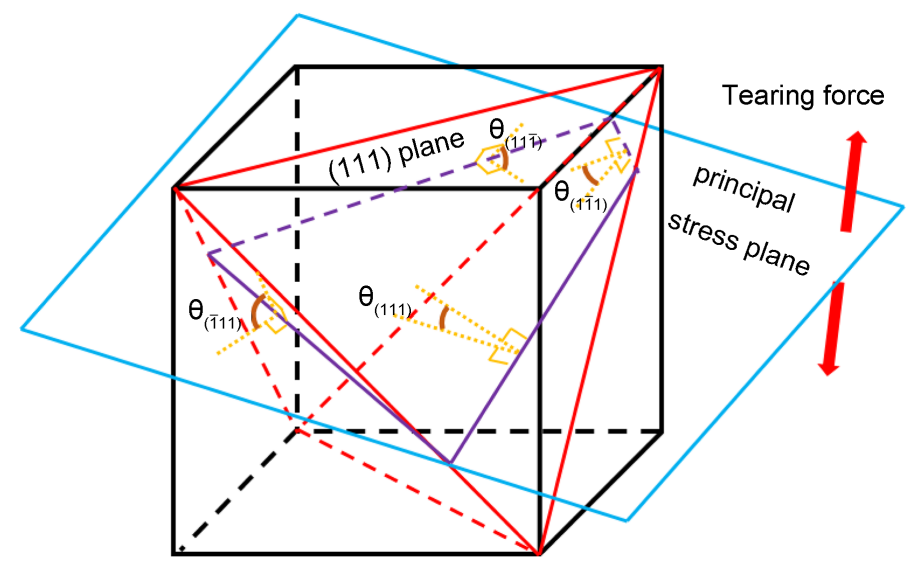

Figure 2. Definition of $\theta$.

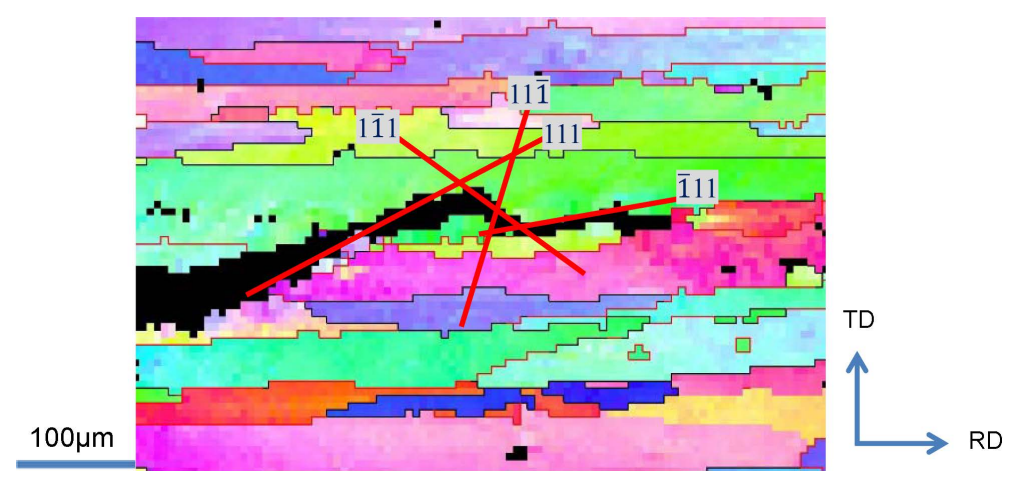

Figure 3. Intersection lines of the $4\{111\}$ planes and the sheet plane in grain B.

Table 1. $\theta$ of each $\{111\}$ plane.

\begin{tabular}{cccccccc}
\hline & \multicolumn{3}{c}{ Euler angles } & & Miller indices & $\begin{array}{c}\theta \text { (Angle between } \\
\text { the principal stress plane) }\end{array}$ \\
\hline$\varphi_{1}$ & $\Phi$ & $\varphi_{2}$ & $\{\mathrm{uvw}\}$ & $\langle$ hkl $\rangle$ & 111 & $\overline{1} 111 \overline{1} 11 \overline{1}$ \\
\hline Grain A & 289.140 & 38.773 & 70.21 & $\{3,1,4\}$ & $\langle 15,-1,-11\rangle$ & 66.49 & 43.3250 .5160 .63 \\
Grain B & 102.842 & 39.348 & 277.39 & $\{-11,2,14\}$ & $\langle 14,-7,12\rangle$ & 62.87 & 50.5937 .1072 .94 \\
Grain C & 49.646 & 27.581 & 294.75 & $\{-2,1,4\}$ & $\langle 12,4,5\rangle$ & 61.19 & 53.5175 .6134 .10 \\
Grain D & 143.167 & 23.512 & 221.12 & $\{-1,-1,3\}$ & $\langle 10,-1,3\rangle$ & 61.08 & 69.2750 .9440 .56 \\
Grain E & 330.275 & 11.894 & 26.38 & $\{1,2,10\}$ & $\langle 10,0,-1\rangle$ & 44.88 & 59.8750 .8464 .86 \\
\hline
\end{tabular}


It's all know that the close-packed plane of f.c.c. metal is $\{111\}$. This atom arrangement has great influence in behavior of materials which leads to anisotropic of a crystal. As a consequence, a crystal can be torn easier apart by $\{111\}$ than other directions because the connection of grains in $\{111\}$ plane is the closest and $\langle 111\rangle$ directions have the least bonding energy. The interatomic forces between atoms must be overcome in order to tear the two atom plane. The more distant of two atom plane, the more energy will be consumed. It can be seen in grain $\mathrm{B}$, the crack change their routes into another direction even though inside the grain. But it still along intersecting lines of $\{111\}$ plane and the sample surface. This phenomenon may attribute to independent critical stress of different direction, which is identified by molecular dynamics simulation within a single crystal [17]. Slip occurs in $\{111\}$ plane first and soon apart from each other.

It can be inferred from above, when crack come across the grain boundary and the orientation of the grain in front of the crack tip is different; the crack propagation will also be different. As is shown in Figure 4, when the crack direction differs widely from the $\{111\}$ plane through grains, the crack propagation may change the direction to the $\{111\}$ plane, because the fracture in $\{111\}$ plane is easier than others. When the crack enters another misaligned grain, direction changing continues. That also leads to the crack behaving not a straight line. The curved crack increased the surface of the cracking plane. During this procedure, more energy would be consumed due to the extra surface where dislocation cut through extra particles.

The $\theta$ of $\{111\}$ plane provides a good prediction of crack propagation path. By testing the grains orientation, resistance level of crack propagation can be estimated. Each $\theta$ can be considered as an energy barrier. Crack propagation always prefers the way with less energy consumption. So turning of a crack direction may occur in order to choose an easier way. If a material has a lot of high $\theta$ $\{111\}$ planes, the resistance from cracking is strong. Furthermore, when using the appropriate processing method to change the grains orientation, tear properties as well as fracture toughness can be improved. This finding is based on the tearing crack of 2024 aluminum alloy, but it can be applied to other aluminum alloy, other f.c.c metal even other materials.

\section{Conclusion}

A definition of $\theta$ explained the crack propagation path of tearing, which has a lot
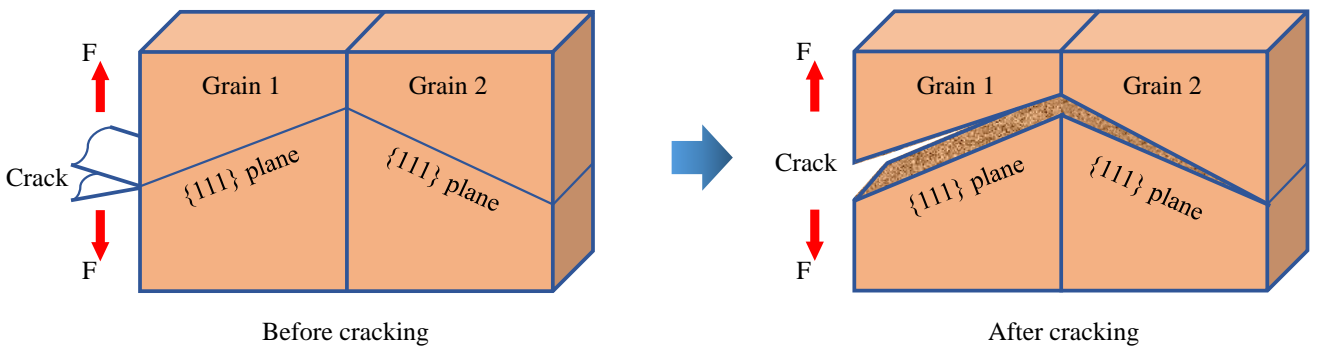

Figure 4. Crack propagation through grains with different orientation. 
to do with the grain orientation. If a grain's $\{111\}$ plane paralleled to the principal stress plane, it's easy to become the path of the crack. On the other hand, if all $\{111\}$ planes diverge the principal stress plane, it's hard to fracture corresponding with a high $\theta$. Crack follows the $\{111\}$ plane may due to the highest critical stress. This phenomenon is not only applied inside the grain but also intergranular crack. To go further, the texture with high $\theta$ makes the materials tougher.

\section{Acknowledgements}

This work is supported by the Major State Research Program of China (Project No. 2016YFB0300901) and the Chinese National Science Foundation (Project No. 51375503).

\section{References}

[1] Griffith, A.A. (1921) The Phenomena of Rupture and Flow in Solids. Philosophical Transactions of the Royal Society of London Series A, Containing Papers of a Mathematical or Physical Character, 221, 163-198.

https://doi.org/10.1098/rsta.1921.0006

[2] Flügge, S. (1958) Elasticity and Plasticity/Elastizität und Plastizität. Springer Berlin Heidelberg, Berlin.

[3] Herbig, M. (2011) 3D Short Fatigue Crack Investigation in Beta Titanium Alloys Using Phase and Diffraction Contrast Tomography. INSA de Lyon, Lyon.

[4] Zhou, P., Zhou, J., Ye, Z., Hong, X., Huang, H. and Xu, W. (2016) Effect of Grain Size and Misorientation Angle on Fatigue Crack Growth of Nanocrystalline Materials. Materials Science and Engineering: A, 663, 1-7. https://doi.org/10.1016/j.msea.2016.03.105

[5] Wu, S.C., Yu, C., Yu, P.S., Buffière, J.Y., Helfen, L. and Fu, Y.N. (2016) Corner Fatigue Cracking Behavior of Hybrid Laser AA7020 Welds by Synchrotron X-Ray Computed Microtomography. Materials Science and Engineering. A, 651, 604-614. https://doi.org/10.1016/j.msea.2015.11.011

[6] Proudhon, H., Li, J., Wang, F., Roos, A., Chiaruttini, V. and Forest, S. (2016) 3D Simulation of Short Fatigue Crack Propagation by Finite Element Crystal Plasticity and Remeshing. International Journal of Fatigue, 82, 238-246. https://doi.org/10.1016/j.ijfatigue.2015.05.022

[7] Zhang, T., Bao, R., Lu, S. and Fei, B. (2016) Investigation of Fatigue Crack Propagation Mechanisms of Branching Crack in 2324-T39 Aluminum Alloy Thin Plates under Cyclic Loading Spectrum. International Journal of Fatigue, 82, 602-615. https://doi.org/10.1016/j.ijfatigue.2015.09.017

[8] Lavigne, O., Gamboa, E., Luzin, V., Law, M., Giuliani, M. and Costin, W. (2014) The Effect of the Crystallographic Texture on Intergranular Stress Corrosion Crack Paths. Materials Science and Engineering. A, 618, 305-309. https://doi.org/10.1016/j.msea.2014.09.038

[9] Culbertson, D. and Jiang, Y. (2016) An Experimental Study of the Orientation Effect on Fatigue Crack Propagation in Rolled AZ31B Magnesium Alloy. Materials Science and Engineering: A, 676, 10-19. https://doi.org/10.1016/j.msea.2016.08.088

[10] Lavigne, O, Gamboa, E., Luzin, V., Law, M., Giuliani, M. and Costin, W. (2014) The Effect of the Crystallographic Texture on Intergranular Stress Corrosion Crack Paths. Materials Science \& Engineering: A, 618, 305-309. 
https://doi.org/10.1016/j.msea.2014.09.038

[11] Sabnis, P.A., Forest, S. and Cormier, J. (2016) Microdamage Modelling of Crack Initiation and Propagation in FCC Single Crystals under Complex Loading Conditions. Computer Methods in Applied Mechanics and Engineering, 312, 468-491. https://doi.org/10.1016/j.cma.2016.04.018

[12] Li, F., Liu, Z., Wu, W., Xia, P., Ying, P., Zhou, Y., et al. (2017) Enhanced Fatigue Crack Propagation Resistance of Al-Cu-Mg Alloy by Intensifying Goss Texture and Refining Goss Grains. Materials Science and Engineering. A, 679, 204-214. https://doi.org/10.1016/j.msea.2016.10.003

[13] Wei, L., Pan, Q., Huang, H., Feng, L. and Wang, Y. (2014) Influence of Grain Structure and Crystallographic Orientation on Fatigue Crack Propagation Behavior of 7050 Alloy Thick Plate. International Journal of Fatigue, 66, 55-64. https://doi.org/10.1016/j.ijfatigue.2014.03.009

[14] Yan, L. and Fan, J. (2016) In-Situ SEM Study of Fatigue Crack Initiation and Propagation Behavior in 2524 Aluminum Alloy. Materials \& Design, 110, 592-601. https://doi.org/10.1016/j.matdes.2016.08.004

[15] Li, F., Liu, Z., Wu, W., Xia, P., Ying, P., Zhao, Q., et al. (2016) On the Role of Texture in Governing Fatigue Crack Propagation Behavior of 2524 Aluminum Alloy. Materials Science and Engineering: A, 669, 367-378. https://doi.org/10.1016/j.msea.2016.05.091

[16] Wen, W., Cai, P., Ngan, A.H.W. and Zhai, T. (2016) An Experimental Methodology to Quantify the Resistance of Grain Boundaries to Fatigue Crack Growth in an AA2024 T351 Al-Cu Alloy. Materials Science and Engineering: A, 666, 288-296. https://doi.org/10.1016/j.msea.2016.04.071

[17] Sung, P.-H. and Chen, T.-C. (2015) Studies of Crack Growth and Propagation of Single-Crystal Nickel by Molecular Dynamics. Computational Materials Science, 102, 151-158. https://doi.org/10.1016/j.commatsci.2015.02.031

\section{Scientific Research Publishing}

Submit or recommend next manuscript to SCIRP and we will provide best service for you:

Accepting pre-submission inquiries through Email, Facebook, LinkedIn, Twitter, etc. A wide selection of journals (inclusive of 9 subjects, more than 200 journals)

Providing 24-hour high-quality service

User-friendly online submission system

Fair and swift peer-review system

Efficient typesetting and proofreading procedure

Display of the result of downloads and visits, as well as the number of cited articles

Maximum dissemination of your research work

Submit your manuscript at: http://papersubmission.scirp.org/

Or contact eng@scirp.org 